Revista Destaques Acadêmicos, Lajeado, v. 10, n. 4, 2018. ISSN 2176-3070

DOI: http://dx.doi.org/10.22410/issn.2176-3070.v10i4a2018.1988

http://www.univates.br/revistas

\title{
ELABORAÇÃO DE PÓRTICO DE CONCRETO ARMADO AO CONCURSO APARATO DE PROTEÇÃO AO OVO
}

\author{
Gabriela Trevisol Loss ${ }^{1}$, Marina Valduga ${ }^{2}$, Roberta Diehl ${ }^{3}$, \\ Willian Poleto Zanon ${ }^{4}$
}

\begin{abstract}
Resumo: O presente artigo relata a construção de um pórtico espacial de concreto armado, com dimensões definidas e volume limitado, cujo nome é Aparato de Proteção ao Ovo (APO), sendo parametrizado segundo as normas e técnicas estabelecidas pelo concurso de mesmo nome, promovido pelo Instituto Brasileiro do Concreto (IBRACON). O pórtico foi desenvolvido com o intuito de suportar o maior número de cargas possíveis, além de apresentar uma baixa deformação. Para sua confecção foi utilizado o cimento CP V ARI, sílica ativa, areia fina, aditivo superplastificante e microfibra de polipropileno. Além da confecção do pórtico, foram moldados dois corpos de prova, para posteriormente conhecer suas resistências através do ensaio de compressão. A estrutura construída passou pelo ensaio de carregamento dinâmico com cargas crescentes de impacto, até a sua ruptura, resistindo a golpes de até 2,0 metros de altura, com uma carga de $15 \mathrm{~kg}$. Os dois corpos de prova realizados e rompidos no mesmo dia do APO obtiveram as resistências de 49,28 MPa e 75,61 MPa.
\end{abstract}

Palavra-chave: Concreto armado. Dosagem de concreto. Materiais. Aparato de Proteção ao Ovo.

\section{Introdução}

O aparato de proteção ao ovo (APO) é uma estrutura constituída por concreto armado, submetido a um ensaio de carga dinâmica. O presente artigo foi desenvolvido na disciplina de Concreto Armado II, onde o principal objetivo foi fazer com que o APO apresentasse resistência suficiente para proteger um ovo cozido sob a estrutura.

1 Graduanda em Engenharia Civil. Universidade do Vale do Taquari - Univates.

2 Graduanda em Engenharia Civil. Universidade do Vale do Taquari - Univates.

3 Graduanda em Engenharia Civil. Universidade do Vale do Taquari - Univates.

4 Graduanda em Engenharia Civil. Universidade do Vale do Taquari - Univates. 
O APO faz com que saibamos aproveitar o possível das propriedades do concreto armado junto com a capacidade de quem realiza no desenvolvimento de cada parte de uma estrutura para resistir a grandes cargas dinâmicas.

O aparato simula a construção de pilares e vigas de uma obra de engenharia, em escala reduzida, em que o aluno pode observar a ação causada pela compressão, tração e torção da peça.

Durante o desenvolvimento do projeto, buscaram-se alternativas e materiais que pudessem aumentar a resistência do aparato, assim como a sílica e o aditivo, podendo assim, ampliar os conhecimentos e evoluir de forma significativa, tanto na vida acadêmica, quanto na vida profissional.

A resistência do APO foi avaliada mediante aplicação de impactos de cargas verticais de alturas gradativamente variáveis, sendo a cada golpe, aumentada em 50 centímetros. A finalidade da avaliação da resistência associada a cada aparato está na avaliação e análise crítica quanto a construção do pórtico e seu comportamento durante e após a ruptura, além da bonificação do aparato que obtiver maior resistência.

A elaboração deste projeto ficou à critério dos participantes quanto a decisão de materiais utilizados, respeitando a regulamentação do edital, elaborando um traço de concreto para adquirir uma estrutura capaz de suportar cargas variáveis de maior amplitude.

Para a preparação dos concretos para este trabalho, deve-se buscar por concretos mais resistentes. Para esse projeto foram testados traços com a utilização de diversos materiais, como aditivos, adições e fibras. Considerando a estrutura em escala reduzida a ser concretada, pode-se definir a dimensão máxima das partículas dos agregados graúdo e miúdo e a fluidez requerida para a argamassa no estado fresco.

Deste modo, o desenvolvimento do presente projeto ressalta a criatividade e investigação de casos para a vida profissional, propiciando buscar informações e ideias de outras pessoas ligadas a construção, troca de informações com laboratoristas, tecnologia de materiais e aplicação de conteúdos vistos durante a graduação, desenvolvendo o lado criativo e empreendedor.

Esse trabalho foi um teste de um possível concurso, visando a implementação do mesmo, nos moldes do realizado no IBRACON.

\section{Materiais e Métodos}

\subsection{Materiais}

Os materiais utilizados para a produção do APO são o cimento CPV ARI, sílica ativa, areia fina, aditivo superplastificante e microfibra de polipropileno, sendo suas proporções, apresentadas com detalhes na Tabela 01. Os mesmos 
foram fornecidos pela universidade Univates, com exceção da microfibra, fornecida pela empresa Conpasul.

Tabela 1 - Proporção dos constituintes na preparação do APO

\begin{tabular}{c|c}
\hline Material & Quantidade \\
\hline Cimento CP V ARI & $3.486,80 \mathrm{~g}$ \\
\hline Sílica Ativa & $815,70 \mathrm{~g}$ \\
\hline Areia Fina & $2.563,80 \mathrm{~g}$ \\
\hline Microfibra de Polipropileno & $57,50 \mathrm{~g}$ \\
\hline Aditivo Superplastificante & $49 \mathrm{ml}$ \\
\hline Água & $290 \mathrm{ml}$ \\
\hline
\end{tabular}

Fonte: Autores (2018).

O cimento Portland CP V de alta resistência (ARI) da empresa Cimpor e a sílica ativa, que segundo TECNOSIL (2018) proporciona ao concreto baixa porosidade, maior resistência mecânica e aderência entre a pasta e armadura, foram empregados como materiais aglomerantes devido a sua disponibilidade na região.

A areia natural fina possui granulometria entre 0,6 e $0,075 \mathrm{~mm}$, para gerar menor quantidade de vazios possível. Sendo dos materiais utilizados a que possui maior dimensão, pois de acordo com (PARK et al., 2008) os agregados com maiores dimensões reduzem a resistência à tração devido a menor aderência às fibras. E a microfibra utilizou-se pois, conforme SENISSE (2010) garante ao concreto maior resistência ao impacto e desgaste, além de que cria-se microfissuras para evitar que surja uma grande fissura que pode ocasionar o rompimento da estrutura.

O aditivo superplastificante a base de policarboxilato adotado garante maior fluidez, viscosidade e evita a segregação da mistura do concreto. Segundo MEHTA e MONTEIRO (2014) com a utilização desse aditivo ocorre à redução da relação água/cimento, aumento da resistência à compressão proporcional a essa redução e a aceleração da velocidade de hidratação.

\subsection{Métodos}

O pórtico elaborado possui uma área plana, bem regular, e deve possuir precisão de medidas em suas diversas faces, pelo fato de ser encaixado no gabarito para ficar alinhado ao dispositivo de aplicação da carga. Em todos os pontos da base ao topo possui altura máxima de $250 \mathrm{~mm}$, larguras mínimas de $50 \mathrm{~mm}$, e comprimento total de $400 \mathrm{~mm}$, como ilustra a Figura 1. 
Figura 1- Dimensões do pórtico

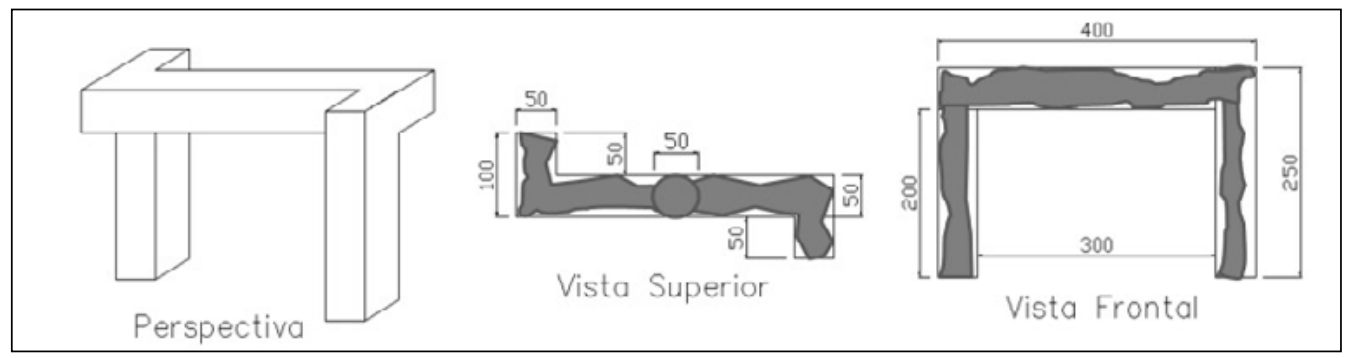

Fonte: IBRACON (2018).

A fôrma para moldagem do pórtico foi confeccionada em madeira do tipo MDF, com $18 \mathrm{~mm}$ de espessura, cortada nas dimensões definidas, sendo admitida uma margem de erro de no máximo $1 \mathrm{~mm}$, e fixadas por parafusos para facilitar a desmontagem, como ilustra a Figura 2.

Nas faces internas utilizou-se uma camada de desmoldante, óleo de origem vegetal, para facilitar a desforma e evitar a penetração da pasta na forma.

Figura 2 - Fôrma da estrutura

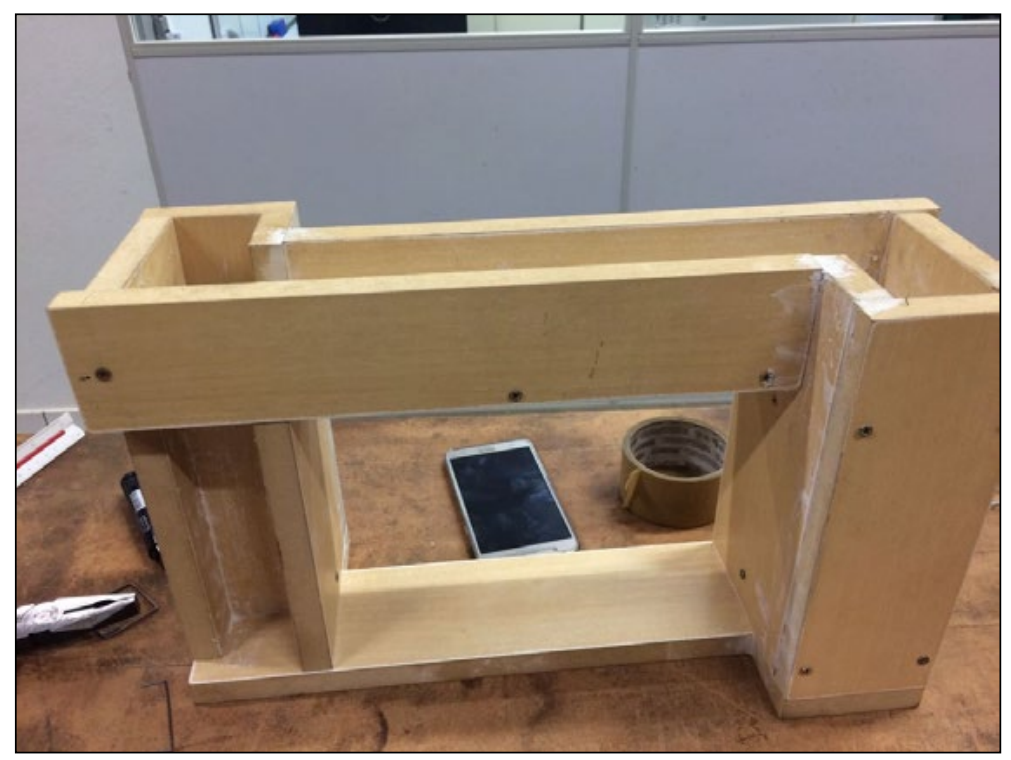

Fonte: Autores (2018).

A armadura foi projetada para resistir os esforços de tração e torção, respeitando as condições impostas pelo edital do concurso do APO, fornecido pelo IBRACON, no ano de 2018. Sendo a armadura longitudinal produzida 
por fios de aço-mola com diâmetro de 1,65 mm, fornecidos pela universidade Univates, com 6 fios dobrados que compõem o tamanho total do pórtico, sem emendas.

Utilizou-se diferentes dobras para contribuir com uma maior resistência, sendo duas barras com a dobra conforme a Figura 3.

Figura 3 - Dobra

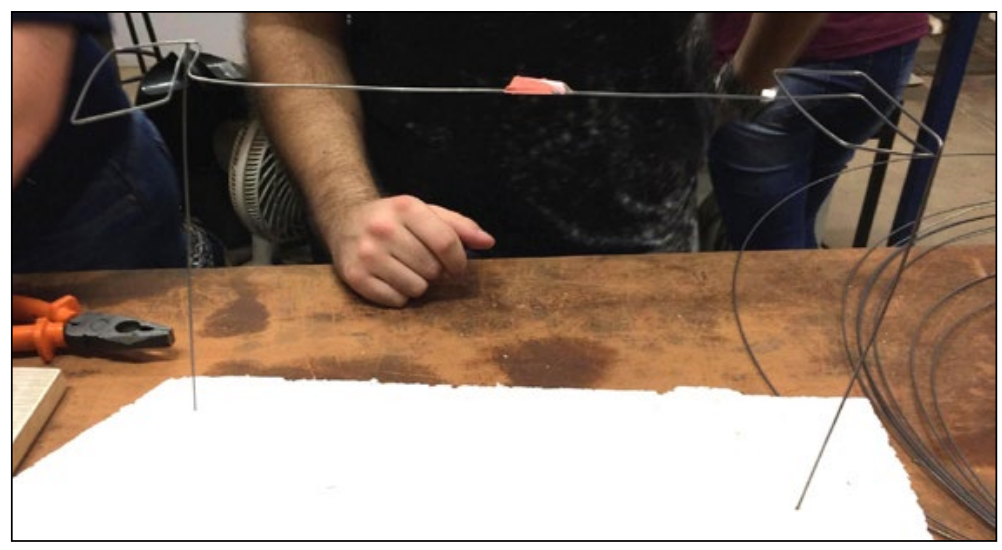

Fonte: Autores (2018).

Para a armadura transversal foram utilizados 11 estribos de fio de aço, com o diâmetro de 1,2 $\mathrm{mm}$ distribuídos ao longo de todo o pórtico, em pontos estratégicos devido aos esforços e para unir as armaduras longitudinais. Sendo três posicionados sobre cada um dos pilares e o restante dos cinco sobre a viga e no encontro viga-pilar, como mostra a Figura 4.

Figura 4 - Armadura da estrutura

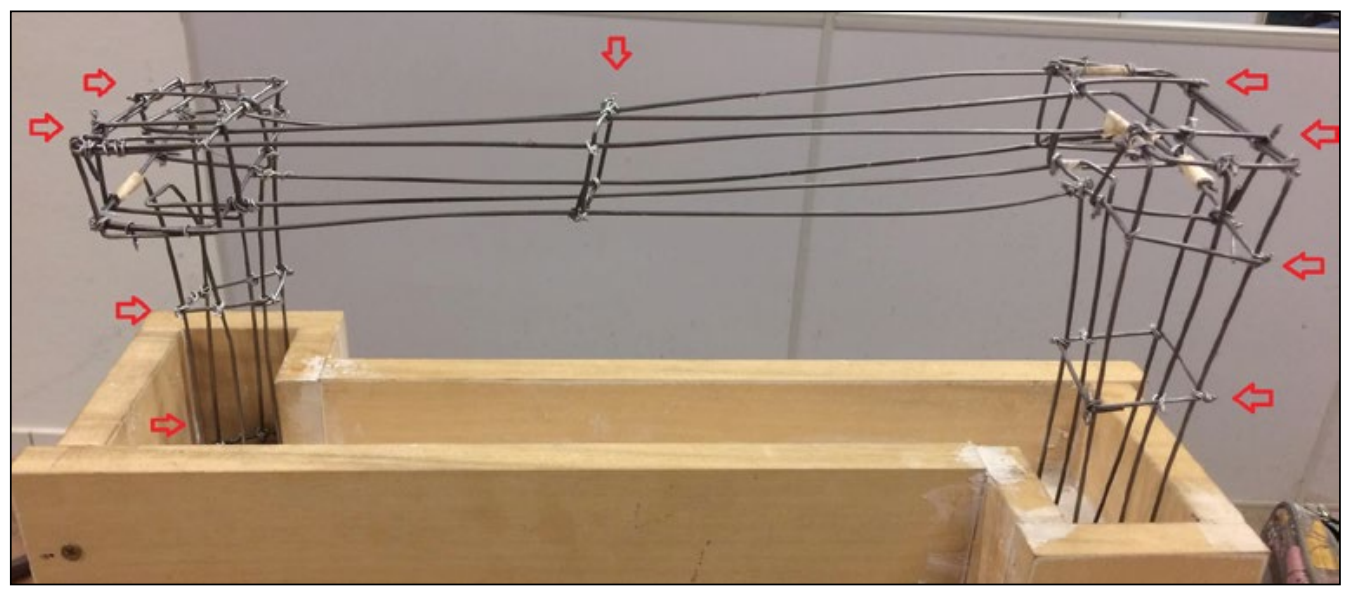

Fonte: Autores (2018). 
Pode-se observar 9 estribos na Figura 4, assim como indicado, sendo que dois localizam-se dentro da fôrma, nos pilares.

A amarração entre os estribos e as barras foram utilizados os fios de aço com o diâmetro de 0,2 $\mathrm{mm}$. A armadura foi posicionada dentro da fôrma, mantendo o cuidado de respeitar o espaço de cobrimento, estipulado em aproximadamente $5 \mathrm{~mm}$.

A concretagem foi realizada em um misturador mecânico, onde inicialmente foram adicionados uma parte da quantidade de cimento, sílica ativa e água até obter-se uma mistura homogênea. Em seguida, foi colocado uma parte do aditivo superplastificante na mistura. Esse processo se repetiu, porém foi sendo acrescentado na mistura a areia, sempre em pequenas quantidades, seguidas por adição de água, a fibra e o aditivo superplastificante, a fim de garantir o concreto desejado.

No momento da concretagem do aparato, utilizou-se um vibrador de mesa para melhor adensar o concreto, devido a densidade da armadura, pois possivelmente, o concreto enfrentaria dificuldades em atingir todos os pontos da fôrma, tendo grandes chances de ocorrer falhas na concretagem (bicheiras). Além disso, foram moldados dois Corpos de Prova (CP) com dimensões de $10 \mathrm{~cm}$ de altura por $5 \mathrm{~cm}$ de diâmetro, de acordo com a NBR 5738 (ABNT, 2003).

Após a concretagem, o APO e os CP foram desformados 24 horas após o início do processo de cura, sendo estes colocados logo em seguida à câmara úmida, onde permaneceram até o dia no qual foram rompidos.

\section{Resultados e Discussões}

Para a obtenção dos resultados, o primeiro passo inclui a análise da eficiência da argamassa confeccionada. Para isto, os dois CP foram submetidos ao teste de compressão, respectivamente, em 21 e 28 dias após seu processo de fabricação (05/04/2018). Este processo foi feito por funcionários do Laboratório de Tecnologias da Construção (LATEC) da Universidade do Vale do Taquari (UNIVATES. Os resultados obtidos do teste estão apresentados na Tabela 2.

Tabela 2 - Resultados do Teste de Compressão para os Corpos de Prova

\begin{tabular}{|c|c|c|c|c|c|}
\hline $\begin{array}{l}\text { Corpo de } \\
\text { Prova }(\mathrm{CP})\end{array}$ & $\begin{array}{l}\text { Área } \\
\left(\mathrm{mm}^{2}\right)\end{array}$ & $\begin{array}{c}\text { Força } \\
\text { Máxima (kgf) }\end{array}$ & $\begin{array}{c}\text { Resistência à } \\
\text { Compressão (MPa) }\end{array}$ & $\begin{array}{l}\text { Idade } \\
\text { (dias) }\end{array}$ & Data \\
\hline 1 & 196,349 & 9867,54 & 49,28 & 21 & $27 / 04 / 2018$ \\
\hline 2 & 196,349 & 15138,29 & 75,61 & 28 & $03 / 05 / 2018$ \\
\hline
\end{tabular}

Fonte: Autores (2018).

Com os resultados obtidos, é possível afirmar que a resistência encontrada aos 28 dias $(75,61 \mathrm{MPa})$ é adequada para a confecção do Aparato de 
Proteção ao Ovo (APO), já que espera-se que um Concreto de Alto Desempenho (CAD) possua resistência entre $50 \mathrm{MPa}$ e $100 \mathrm{MPa}$.

Feita a análise dos corpos de prova, o rompimento do pórtico foi feito no mesmo dia do rompimento do segundo cilindro (03/05/2018). Para este ato, houve auxílio de professores e funcionários do LATEC. A estrutura foi fixada em uma base metálica, presa por elásticos (a fim de evitar deslocamentos) e seu posicionamento foi de forma que o ponto de aplicação de carga fosse exatamente na metade de seu vão principal. A carga utilizada possuía massa de $15 \mathrm{~kg}$ e poderia ser solta, respectivamente, de alturas de $0,5 \mathrm{~m}, 1,0 \mathrm{~m}, 1,5 \mathrm{~m}, 2,0 \mathrm{~m}$ e 2,5m (máximo) em relação ao aparato. Para sucesso completo do teste, a carga deveria ser solta da altura de $2,5 \mathrm{~m}$ por 3 vezes e a estrutura deveria manter sua integridade, totalizando 7 golpes, no máximo. $\mathrm{O}$ teste poderia ser finalizado antes do previsto se houvesse grande deslocamento estrutural ou esmagamento do ovo que estava sob o pórtico. Com o início do teste, os resultados obtidos constam na Tabela 3.

Tabela 3 - Resultados do Teste de Compressão para o APO

\begin{tabular}{|c|c|c|}
\hline Golpe & Altura (m) & Descrição \\
\hline 1 & 0,5 & $\begin{array}{l}\text { Não surgiram fissuras ou sinais de patologias que poderiam } \\
\text { comprometer a estrutura no próximo lançamento. Ovo íntegro. }\end{array}$ \\
\hline 2 & 1,0 & $\begin{array}{l}\text { Surgimento de microfissuras de flexão na parte inferior do vão } \\
\text { principal (maior momento de flexão). Restante da estrutura } \\
\text { não apresenta patologias significativas. Ovo íntegro. }\end{array}$ \\
\hline 3 & 1,5 & $\begin{array}{l}\text { Aumento das fissuras no vão principal com consequente } \\
\text { deformação (tração na parte inferior e compressão na parte } \\
\text { superior). Surgem fissuras de cisalhamento na ligação "vão } \\
\text { principal-vãos intermediários". Pilares com microfissuras nas } \\
\text { partes superiores externas (traseira e lateral). Ovo íntegro. }\end{array}$ \\
\hline 4 & 2,0 & $\begin{array}{l}\text { Viga do vão principal sob forte efeito de flexão (ruptura } \\
\text { maior que } 50 \% \text { e presença de muitas fissuras de cisalhamento } \\
\text { nas extremidades do vão. Pilares apresentam fissuras em } \\
\text { pequena quantidade nas partes superiores externas, sem sinais } \\
\text { significativos de colapso. Vãos intermediários e armaduras de } \\
\text { torção sem patologias significativas. Colapso iminente. Ovo } \\
\text { íntegro. }\end{array}$ \\
\hline 5 & 2,5 & $\begin{array}{l}\text { Colapso total e consequente comprometimento da integridade } \\
\text { estrutural. Esmagamento do ovo. }\end{array}$ \\
\hline 6 & 2,5 & - \\
\hline 7 & 2,5 & - \\
\hline
\end{tabular}

Fonte: Autores (2018). 
A Figura 5 demonstra o estado da estrutura momentos antes do impacto final (quinto lançamento).

Figura 5 - Pórtico após o quarto lançamento

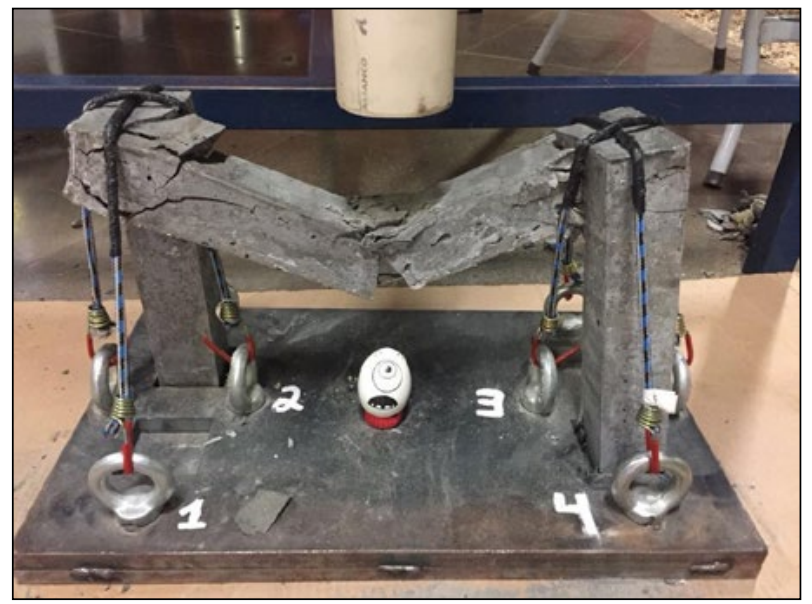

Fonte: Autores (2018).

Após o término do teste e recolhimento da estrutura, foi feita uma análise minuciosa das patologias, conforme ilustram as Figuras 6 e 7, responsáveis pelo colapso estrutural.

Figura 6 - Ruptura de flexão no vão principal

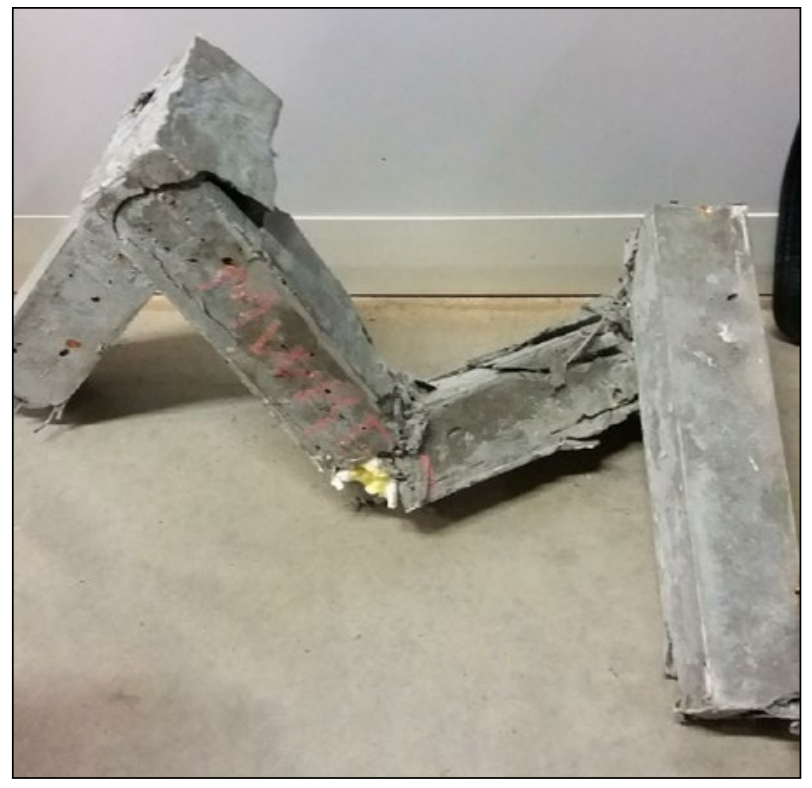

Fonte: Autores (2018). 
Figura 7 - Detalhe entre vão principal - vão intermediário

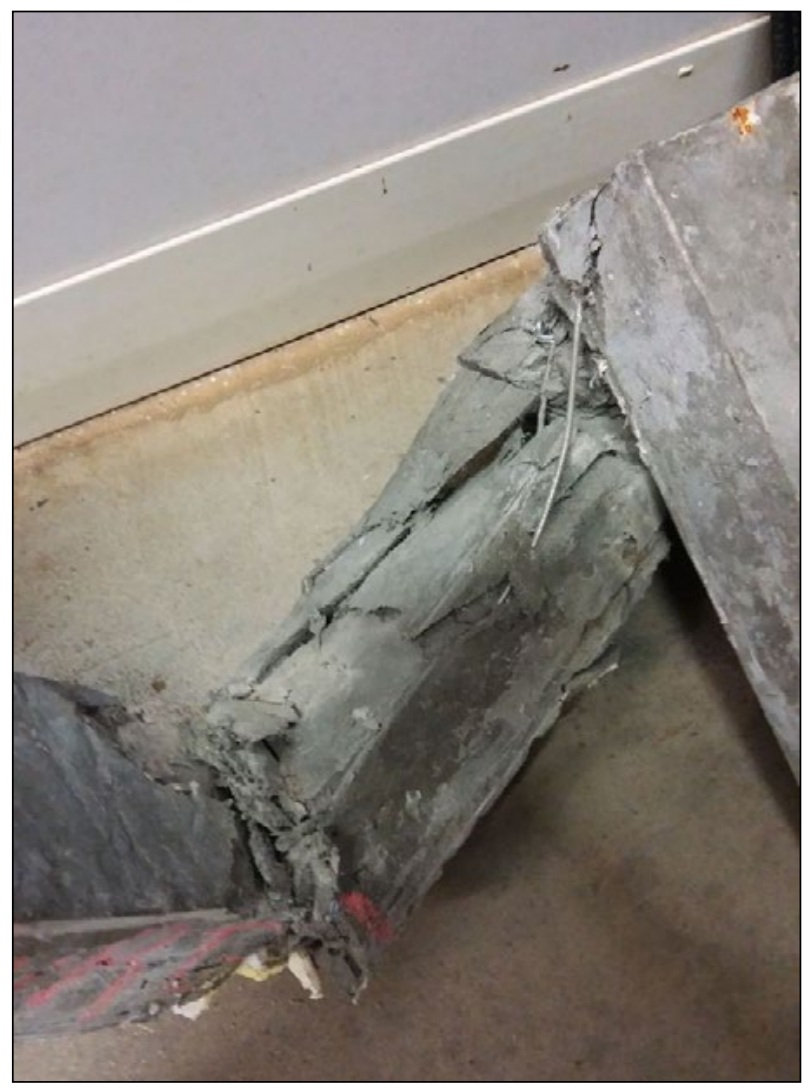

Fonte: Autores (2018).

Verificando-se grande deformação e colapso no vão principal, diferentemente dos vãos intermediários (boa integridade) e pilares, que sofreram com pequenas fissuras, apenas. Com isto, é possível formular algumas hipóteses: o vão principal pode ter absorvido a maior parte dos esforços (transmissão incorreta para os vãos intermediários e pilares) e, desta forma, as fissuras encontradas no elemento são formas de dissipação de tensões internas que, com o aumento de carga, houve o colapso; outra explicação significativa inclui que, possivelmente, havia maior necessidade de estribos no vão principal, que, com a ausência, rompeu. $\mathrm{O}$ aparato, possivelmente, foi dimensionado e/ ou executado de forma incorreta em seu vão principal.

\section{Conclusão}

Analisando os resultados obtidos, pôde-se concluir que o aparato teve um bom desempenho, resistindo a golpes de até 2,0 metros de altura, com uma carga de $15 \mathrm{~kg}$. Acredita-se que a preocupação na hora da montagem da 
armadura em resistir aos esforços de torção, concentrando a maioria dos estribos em suas extremidades, fizeram com que o aparato apresentasse bom resultado. O desempenho do mesmo poderia ter sido melhor, se no traço fosse utilizado uma maior quantidade de fibras, visto que, com a presença das mesmas, no momento em que o aparato recebe os golpes, surgem apenas pequenas fissuras, o que evita o surgimento de uma fissura maior que ocasionaria a ruptura do APO.

O desenvolvimento deste projeto contribuiu de forma positiva e significativamente para a fixação de conceitos e técnicas abordadas ao longo das disciplinas de concreto armado e outras disciplinas da área de Engenharia Civil, deixando ainda mais claro que o desempenho de estruturas de concreto armado depende diretamente da relação entre as resistências do aço e o concreto, bem como a aderência de ambos.

\section{Referências}

MEHTA, P.K.; MONTEIRO,P. J. M. Concreto: microestrutura, propriedades e materiais. 3. Ed. São Paulo: IBRACON, 2014. 782 p.

PARK, J. J.; KANG, S. T.; KOH, K. T.; KIM, S. W. Influence of the ingredients on the compressive strength of UHPC as a fundamental study to optimize the mixing proportion. Second international symposium on ultra high performance concrete. Kassel, Alemanha; 2008. pp. 105-112.

IBRACON. Regulamento do $25^{\circ}$ Concurso - Aparato de Proteção ao Ovo 2018. São Paulo. Disponível em:<http://www.ibracon.org.br/eventos/60cbc/ REGULAMENTO_APO2018.pdf> Acesso em 24 jun. 2018.

SENISSE, J.A.L. Influência do consumo de água, do teor de adição de microfibras de polipropileno, e do tipo de cimento no fenômeno da retração por secagem em concretos empregados em pisos. 2010. 160f. Dissertação (Mestrado em Engenharia). Universidade Federal do Rio Grande do Sul, Porto Alegre, 2010.

Tec Flow - Aditivo superplastificantes para concreto. Grace Construction. Junho, 2015. Disponivel em: <https://gcpat.com/construction/pt-br/Documents/ TECFLOW_2015.pdf >. Acesso em 19 jun. 2018.

TECNOSILBR. Catálogo Sílica Ativa. Disponível em:<http://www.tecnosilbr.com. $\mathrm{br} / \mathrm{wp}$-content/themes/tecnosilbr/download/catalogo-silica-ativa.pdf $>$. Acesso em 19 abril 2018.

. O que caracteriza um concreto de alto desempenho (CAD)?. Disponível em: $<$ http:/ /www.tecnosilbr.com.br/conteudo/?p=130>. Acesso em 13 de jun. de 2018. 